\title{
Research Application Method of Analyzing New Economic Model Followed in Albania
}

\section{PhD Miftar Ramosacaj}

\author{
Prof. Dr. Alba Robert Dumi \\ Math Department, University of Vlora, Ismail Qemali"Albania \\ "Ismail Qemali"VIore University, Albania, University of Tirana, Albania \\ Email: alba.besi12@gmail.com
}

\section{Doi:10.5901/mjss.2017.v8n1p210}

\section{Abstract}

In my topic, I would like to present theoretical approaches and concrete direction of the new economic model that Albania should follow, based on the current situation that Albania experienced in global economy. In this paper, initially, I will present an overview of the Albanian economic transition and then I will suggest a heap of conclusions based on 20 years of history of success and failures. Primarily,concerning Europe means to have clear concepts, in order to build and to consolidate a system of economic and social-capitalistcomprehension. Have you ever thought to raise a question, and more we tried to make a qualitative analysis of policy which responses to specific questions or queries following correctly: what is the most appropriate model for Albania capitalism?Are we building a coherent and structured model or are we building a mosaic of elements of capitalism for Albania, whose portrait we do not know any more and that we didn 't "projected" yet and no one else has done it in a long-term vision? The best response is a response expected of the type as far as our final objective is the European Union, and then our model of capitalism will be European capitalist model, then the problem starts here. Capitalism has some basic principles and rules that form the core of it, but on the other hand each country is profiling capitalism according to the specifications of his choices. France has chosen the model of "capitalism of State", Germany and the Nordic countries "socialdemocraticcapitalism", "liberal capitalism of England" as English-Saxon one, etc.In this regard the experts or politicians, should not reduce any debate, analysis or summary only of certain elements of the system of market, individual freedom, comparative advantages, social policy, which means the role and presence of the state in the economy, system of taxation, social security and the system of pensions, in order to build a port in its entirety capitalist model that we really need in Albania.

Keywords: Economic model, applications, reforms, comparative advantages.

\section{Introduction}

In this regard the experts or politicians, should not reduce any debate, analysis or summary only of certain elements of the system of market, individual freedom, comparative advantages, social policy, which means the role and presence of the state in the economy, system of taxation, social security and the system of pensions, in order to build a port in its entirety capitalist model that we really need in Albania.It becomes important for the fact that in a considerable extent, we have already built "market economy", but meanwhile we have started to build capitalism and profiling its ' model". (Hart, S.L \& Quinn, R.E1993)

And this model does not begin and end only to market and individual freedom, but he needs to be judged by considering the establishment and consolidation of specific institutions, strengthening of democracy and legitimacy of all actors in development. Necessary compromisesof political factors with the psychological and historical memory of each country.

Precisely, these elementsare considered as one of the economist recognitions in the world for its analysis in relation to the models of capitalism. Magnin finds that "the analysis of the trajectory" of the transition of the former communist countries of Central and Eastern Europe, now members of EU testifies for an original form of capitalism emerging, a model really adapted to history and economic reality, as social, political, and psychological one.

Let us refer to the only one and exclusive model or a school like that of "ultra-liberal", "regulation", "institutionalist" to have more holistic perspective, historical and geographical comparative analysis as well as the experience of the problems of other countries of Central and Eastern Europe that are already integrated in the EU. Even Dutch researcher of capitalism models, $\mathrm{H}$. Uterwedde refers that:"It is simply an illusion the practice of importing a ready model and even creating a mosaic with the best sides of different models is an illusion too."

In fact, the truth is that only by understanding and respecting their whole complexity of each model of capitalism 
that already exist in the world, with the pros and cons of its benefits can be drawn the necessaryexperience from the others.

By J. Delors "specific national cultures and history of each country is the main opponent of a common capitalist in European cycle". Models of capitalism in their integrity and coherence of the concepts originate in their national histories and in relation to freedom".

The first definition of freedom is English, "is free he who does not belong to any person" and business relationships and ways of functioning of the labor market, as one of the most essential figures to Englishcapitalism as Angle-Saxon ones. The symbolic essence of this freedom, allows everyone to change at any moment in his work or to open a new business in complete freedom. The essence of this philosophy is "if' you do not have success, the main responsibility lies in your ability and efforts to achieve success".

In England, the model of capitalism is the same with "freedom of everyone to access, to develop, and to change or close his business and employment policies" perfected and effective in their results by Margaret Thatcherand Tony Blair.

The issue of the new economic model, vision and structure as well as other significant issues as development priorities of a country, in the context of global and regional level and the sustainability of economic growth is linked to employment with deep structural reforms, with the green economy, education and innovation; issues that describe theoretical first part of this study.(Hart, S.L \& Quinn, R.E1993)

\section{Literature Review and Hypotheses}

This is not a purely theoretical connection between politics and the economy. This fact is also true and proved several times, in different places in our country.These policies are already affecting significantly and adversely the country's economy, public finances and social status. This impact, this political crisis with the economic and social situation, the more time passes the greater is the cost and consequences.

A prolonged political crisis could positively influence decision making and implementation of successful anti-crisis consensus, from the elected bodies and from the Albanian Parliament for the adoption of laws and fiscal policy, the budget, the Court of Accounts, for the implementation of the fiscal amnesty. Political crisis also are accompanied by a decline of trust in state institutions and in particular the performance of its functions of economic character. Source: INSTAT Progress Report.

They have played a negative role in: curbing growth, operations and activities of private business and keeping him in host position, the curbing foreign of direct investment, the collapse of confidence in the banking financial institutions in the country and foreign markets, increasing the social difficulties, unemployment, poverty, reduction of family budgets; facing so the rising price of energy, drinking water and essential goods for living.

\subsection{Repeated political crisis and their impact on the economic and business cycle}

Policy direction of the economy and public finance management, especially in the past two years led to the destruction of economic and financial balances in the country especially in the decline of economic growth (0-3\%); growing budget deficit at 7.6\% in 2009 and public debt at around 62\% of GDP, the decline of direct investment in the economy, the rising of unemployment and deepeningof asymmetry between economic growth and unemployment. (Hart, S.L \& Quinn, R.E1993)

There are some development steeps of growing up the impact of economy like:

I. Government relations with business, the expansion of economic and regulatory reforms and this freedom continues to face a number of problems related to lack of transparency and consumer business, difficulties in obstacles administrative rules.

II. The competitiveness of our economy that has made all reasonable steps could not be repositioned as to regional and wider economy. Our level of competitiveness in international markets show the level of Albanian exports which find market with many difficulties in these markets, despite ongoing liberalization of trade relations with its neighbors.

III. The demographic movements, migration and immigration, the impact on the real economic and social development in the country. Half of the country's population currently lives in a different country from the one who lived in 1990. During the last 20 years our population has greatlymigrated. According to the World Bank, about $20 \%$ of the adult population is displaced within the country, while $35 \%$ of the active population currently is immigrant. These synthetic indicators of the Albanian Migratory flows should impose visionary policies and long-term migration, combined with policies of economic development, social development of the country. 


\section{Source: INSTAT Progress Report.}

IV. The structure and profile of poverty has changed, has deepened, especially in the northeastern areas and rural areas. The budgets, especially pensioners, people in need and families with low incomes, continue to be aggravated.It is enough to mention that about $12,4 \%$ of the population live on less than $\$ 2$ per capita, not getting the minimum (around 360,000 people from 3.2 million people live on $\$ 2$ a day and 88,000 of them .

V. They live just $\$ 1$ a day; the latest estimates of the World Bank, although they confirmed the gradual reduction of poverty and more or less has been in satisfactory level: from 22.5\% in 2002 (INSTAT 2002) to $18.5 \%$ in 2005 (INSTAT 2005) and 12.5\% in 2008 (INSTAT) estimated that policy programs and measures in the fight against poverty have not been very effective. Issues of efficiency and the impact of the weak in the fight against poverty are found in the implementation of the Economic program aid.Source: INSTAT Progress Report.

VI. The Albania ruling political class in view of resource utilization and motivation and human resources (public administration) has been relatively back to the future development needs of the country. This backwardness of the political class and the ruling has caused and prompted the poor performance of administrators and public officials in Albania, among others who have suffered the consequences of the policies of recruitment and training of institutional capacity.

VII. After already 20 years of transition are made available to the economy and other areas of national development an entire generation of human resources entirely new form of mentalities with contemporary education, with managerial skills and leadership with new vision and economic development, they are victims of politics based not on merit but on party militancy.

Another unresolved issue is missing in the system reform of social security and health, which cannot be considered as an important element of the new economic model of the Albanian post- transition. The role of statistical information and independent institutions (INSTAT), financial (MF and Bank of Albania) and social indicators has been somewhat dictated why not harmonized by turning in many cases, not only in a non -transparent instrument, but also as source of not realistic information that brings a great confusion.

The capacity of public administration was weak; the system was highly politicized. Corruption was pervasive in every facet of the public sector. Citizens feared the public administration and did not trust it to provide even the most basic services in a fair or impartial way.(Blake,R.R\&Mounton, J.S.)

\subsection{Research Goal and data collected}

But it seems that the time and content of this model is coming to an end in the sense that many of the elements and his energies apparently reached their maximum and the result already are running out for another period of 10 or 20 years in the future.

H1: Currentglobaleconomic and financial crisis has a direct impact of the Albanian economy and finances. There are highlighted some cardinal problem: how sustainable is our economic growth?

H2: Do we have a structured economy which could go towards a long-term sustainable development?

The direct and indirect effects of the international economic-financial crisis can assume one or many years, and then we must deal with normality, it is estimated that this remains our most serious problem. By 2008-2009 the Albanian economy could have a lower growth than its trend of several years, and this is "justified" as a result of the global crisis, but the big question seems to arise just after this period.

Ensuring sustainable growth means that how will we be able to identify "new fuel sources and increase economic" or "substitute" some current sources of growth in short-term periods and in mid -time.

H3: How will we eliminate or decrease the high trade deficit and payments? How would we restructure the rural space in Albania dominated by agricultural mini-farms?

H4: How would you restructure and modernize Albanian business that still reflects enough the archaic informal element?

What are the best structural policies that convert us to the European economy and where we aim to integrate? Who will be sectors that will make the "motor"in Albanian economy in the coming years?

In this survey we aim to identify that there is a significant decline in economic growth, there is freezing real increase in budget revenues, there is also deepening budget deficit, increase of the stock debt, worsening trade balance, decline in lending to the economy, remittances are also in decline, while the EURO and USD continue rise toward Albanian(ALL).These indicators are enough symptoms of the concerns why the economic growth in future periods may be difficult and will require more time to return to levels before the crisis. Without high rates of economic growth every 
socialandeconomic challenge, integration of our country becomes more difficult.

"According to the report of the "Standard \& Poor" published in the June 2010 general government debt, issued in two-thirds in local currency, is expected to be equal to 57\% of GDP at the end of 2010 . Further debt is 2.7 times higher than the annual income of the government and this is one of the highest debts of countries that we appreciate"1.

\subsubsection{Research Goal}

The cost of debt in 2010 rose to about 7-8 milliard compared with 2009. Given the fact that for years our economy will not be able to achieve economic growth of 6-8\% (according to the IMF not before 2015) we risk to increase the burden of debt and its cost, threatening to become a burdensome stone for the economy, our public finances fragile and Albanian taxpayers.

It imposes stability of public finances in deficit reduction, debt and the cost of financing the economy as the public sector and the private sector. Everywhere today is discussed the problem of public debt and its reduction. (Hersey, P \&Blanchart1982)

Time is very important to recognize the magnitude of the crisis, time is crucial to prevent deterioration of public finances. Any delay or worse any kind of denying approach to the crisis and the risks of interventions in the economy, can bring very serious consequences for future economic developments, social if not political.

The example of the neighboring country, Greece, mismanagement of public finances, low quality of official statistics, high levels of budget deficit, public debt, increased the cost of financing scary the economy and put Greece in the precipice of bankruptcy. (Schumpeter, Joseph 1982)

The consequences of irresponsible policy to make in proper time the necessary reforms, the consequences of populist policies, disturbing size of level of corruption and tax evasion exacerbated Greece's rating in international capital markets, increased costs of financing the economy by imposing even late, but in very critical conditions of extreme social reforms.

Not only Greece but four EU countries have benefited most from EU policies and funding of about 25-30 years after their affiliation, in the first test of a global crisis proved again as the weakest in euro-zone.

Some label PIGS several GIPS-of united Europe, but the disappointment is more than just cynicism. The lesson for policy makers in our country should be clear: EU, access to EU structural funds which are insufficient to meet our future challenges, especially facing a potential crisis.

\section{Data Analysis}

The misuse of populist Euro-Atlantic integration does not hide our problems and potential crises, economic, social and political ones. In this case, they only become more serious and with extraordinary consequences when explode. (Hersey, P \&Blanchart1982)

Thebest harmonization of vision for our future with long-term strategies of economic and social development as well as the sources of the rapid economic growth, it is not an easy task, but that could not be overlooked and even worse to be distorted after every political rotation. Medium-term and annual budget should institutionalize the priorities defined in the strategy (NSDI) and cover the funding priorities of the NSDI. But what is the level of consistency between financial resources and priorities defined in the strategy? How is covered the continuity of indicators of the midterm annual budget.

The deviations from medium-term budget and periodic adjustments in its medium-term budget indicate the opposite and by the problems that the economic and financial situation carries. This finding is reconfirmed by the constant interference of the state budget, its frequent amendments².

We estimate that realistic analyzes over the economic and financial developments in Albania, is taking appropriate steps to restore macro-economic stability and fiscal and will create all the prerequisites for the success of economic stability as he wants to set.

\subsection{The global crisis and the suggestions of specialized institutions}

The new economic model will bring tangible positive effects if it will better support economic growth in the $6-8 \%$, stable growth of revenue $8-10 \%$ every year, control over public spending and increase their efficiency, the decrease of budget

1The consultant's report $S \& P$.

${ }^{2}$ Remind fundamental changes in the budget of 2009-2010 by changing key indicators. 
deficit limits of $3-4 \%$, the gradual reduction of public debt from $60 \%$ to $50 \%$ of GDP, improvement of financial management, strengthening of institutions and public finances as a whole.

In relation to the global crisis, the suggestions of specialized institutions are focused on undertaking fiscal reforms that would provide more revenue to the state budget, the control over public spending and therefore control over the budget deficit and public debt. If I refer to public financial management, performance analysis of macroeconomic and fiscal indicators of our country, we can say that our public finances need immediate intervention, aimed at restoring fiscal balances and the budget.

The state budget is being the main instrument in the hands of the state as a completely public good which it should be used with maximum efficiency. Rational use of expenditure, providing a rationaldistribution, uniform efficient implementation, the use of fiscal policy as an instrument driver for the stimulation of the business, maintaining the balance between financial resources and their performance will provide not only macroeconomic stability but will also provide economic growth rates, the effects of which will be felt in all strata of the population, through effective use of the state budget.

The economic stability is being considered as a public good. It does not represent a set of simple statistical indicators, but affect positively or negatively on economic growth and increase the level of life. The investment and public spending should be aimed at maximum benefit in using their best increase of the efficiency of education, public health prophylaxis, preservation and regeneration of natural resources.(Schumpeter, Joseph 1982)

The increase of tax revenues in relation to the economy and community demands for more spending necessarily requires a deep reform not only because of the crisis. How can high growth rates ensure in earnings except interventions to stimulate economic growth. The insurance revenues in relation to macroeconomic developments, is basically along the country's macroeconomic stability control and management of public expenditures. For this it is necessary that fiscal policies aimed at creating a favorable business environment, fiscal policy should encourage private initiative $s$ at this stage of development and the difficulties facing our economy. (Schumpeter, Joseph 1982)

The budget is the basic instrument through which the government can provide not only the annual targets for a long-term, but with a rational outcasts and providing maximumbenefit to use resources, giving so the impulse of the development of the country, stimulating business not only through investment infrastructure, but also business participation in implementation of projects. The program of spending can turn into an instrument driver for the local economy, if not used efficiently has direct impact on the budget deficit, public debt, rising inflation with implications for macroeconomic stability. (Hersey, P \&Blanchart1982)

That is why the institutions of international financial IMF and the EU in particular, the disbursement of financial support to Greece, has been conditioned by the decrease of immediate public debt, taking austerity in expenditure control, using strict fiscal policy and short-term social costs and very severe.

\subsection{Lessons from the global crisis for the Albanian economy}

- Complete restructuring of the Albanian economy by considering the effects that the global crisis gave.

- Analysis and measurement of factors from the global crisis that contributed on our economy in order to avoid in case of repetition of global crises

\subsection{Which model Albania should adopt?}

The main concern in economic and social policies undertaken in Albania lies in their coherence and consistency in relation to a selected model. (Hersey, P \&Blanchart1982)

We are all witnesses to the fact that in many cases the politicians are "really excited" and suggest as a solution to rescue the experiences of countries that visit or suggestions of experts from different national and international without deepening enough in qualitative analysis on the coherence of these "formulas " in reality and in relation to our model.

All countries affected by the crisis have taken the responsibility of reducing the budget deficit and public debt, mainly to reduce expenditures, but when this was insufficient, they have increased mainly taxes, immediately.

"The sustainable economic growth and social development and political ones, remain challenges in Albania's postcrisis of international financial conditions. Albanian challenges to achieve the millennium until 2015, consisting of country economy ability to maintain a sustainable level of investment and social development. There has been good progress with agricultural statistics. Since the beginning of 2013 the National Statistics Institute (INSTAT) has been responsible for agricultural statistics. Source: The Census of Agricultural Holdings was conducted in October 2012. 


\section{Conclusions}

It is assessed as really positive the American experience in the capital markets and immediately is asked to make similar policy; excited by German policy and social origin and immediately are suggested institutions to prepare a similar policy; after recognizing the experiences of Hungary, Chile, Hong Kong and immediately is required to apply the same things in Albania in order to attract as much foreign investment without linking this with the whole legal and institutionalcontext of these countries compared to ours.

If aparticular policyin the EU (in agro-food) give positive results, immediately we rush to suggest it as a lifeline for agriculture and agro-industry without deepening our financial arrangements or institutions need to implement it; it seems very effective model of social protection or pension in the Nordic countries that shortly seek to implement it without first watching closely associated with the taxlevel and contributions applied to these countries.

Naturally we get excited from the positive experiences of the small states and governments but did not go further in case of deepening greater decentralization and distribution of significant powers at the local level and the creation of specialized agencies to "replace effectively" the role of state and government in providing services.

Even more problematic is the picture when leaders or economic experts, parts of development patterns strive to unite wanting to "patch" delicate aspects of a policy model or programs of another model without a logical economy of financial consistent in producing so "hybrid models" with long-term negative effects.

One concerning problem in this regard are the content of subject programs in our universities, especially those dealing with the economy and finances. Many of them are equivalent and identified by a scientific formation of teachers that treat these programs and how consistent they are with the consolidated models of the contemporary socio-economic circumstances.

\section{References}

Reader, W.J. Imperial Chemical Industries: A History, vol. 1, 1870-1926. Oxford University Press, 1970.

Schumpeter, Joseph. The Theory of Economic Development. Cambridge, Mass.: Harvard University Press, 1934; Original German Edition, 1911.

Schumpeter, Joseph. Capitalism, Socialism and Democracy. New York: Harper Bros., 1942. Siemens, Georg. Der Weg der Elektrotechnik; Geschichte des Hauses Siemens. Freiburg: Alber, 1961.

Sloan, Alfred P., Jr. My Years with General Motors. Garden City, N. Y.: Double-day, 1964. Woodruff, Philip. The Men Who Ruled India.2 vols. New York: St. Martin's Press, and London: Macmillan, 1954.

Dobbins, G.H \&Platz, S.J. sex differences in leadership: How real are they? Academy of Management Review, 1986, 11(1), 118-127.

Dumi, A. MJESS Roma Italy." EU and Albania reforming stade" vol 3, nr 5, 2013, pp 146

Dumi, A. JERM Roma Italy." Math analyze and SME development" vol 1,nr 1, 2014, pp 8

Fidler, F.E. a theory of leadership effectiveness. New York: McGraw-Hill, 1967.

Gillespie, H.R. An investigation of current management/leadership styles of manufacturing executives in Harris, T.G. the post-capitalist executive: an interview with Peter F.Drucker. Harvard business review, 1993, 71, 114-122.

Hart, S.L \& Quinn, R.E. Roles executives play: CEOs, behavioral complexity, and firm performance. Human Relations, 1993, 46(5), 543574.

Hersey, P \&Blanchart, K.H. Management of organizational behavior: utilizing human resource (4th, ed) Englewood Cliffs, NJ: PrenticeHall, 1982. 